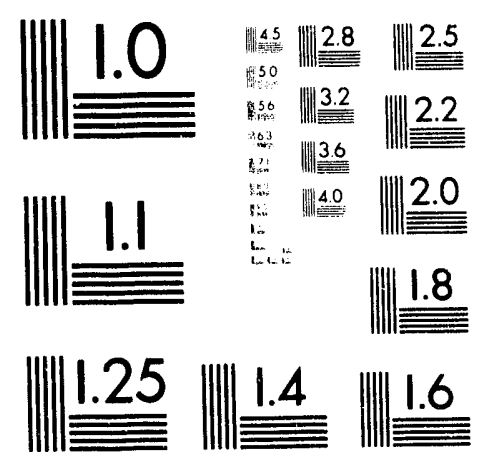



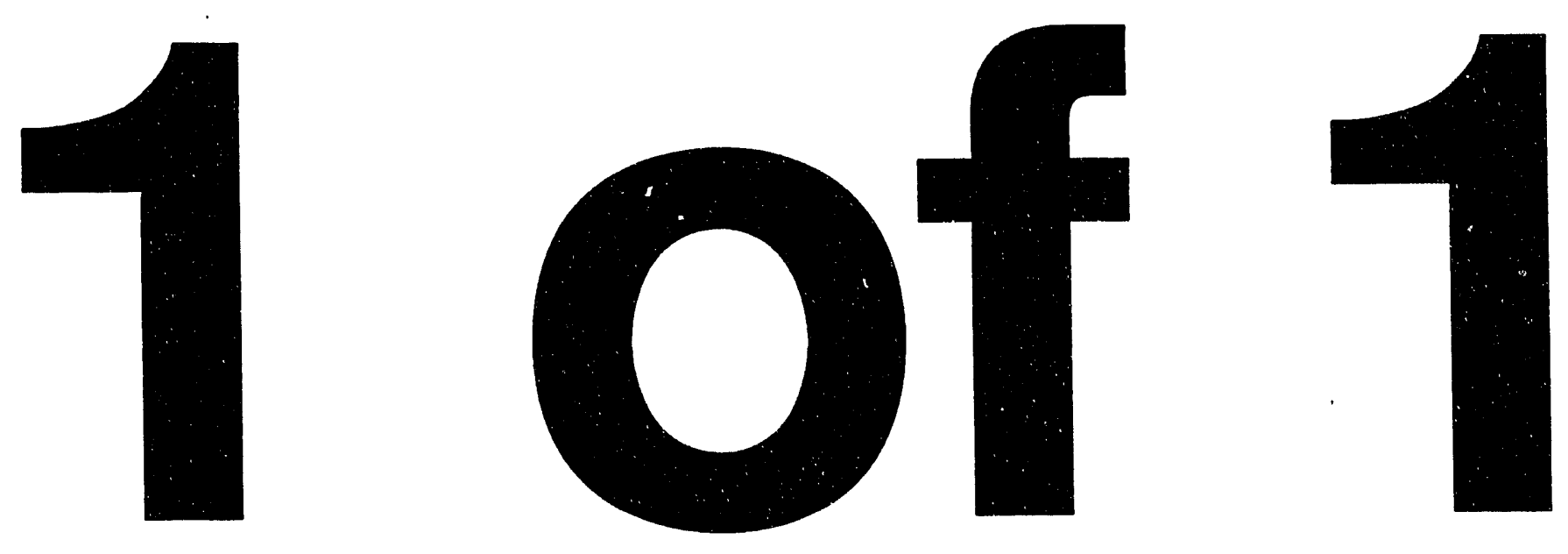


\title{
An In-situ Photocathode Loading System for the SLC Polarized Electron Gun
}

\author{
R. E. Kirby, G. J. Collet, K. Skarpaas \\ Stanford Linear Accuierator Center \\ Stanford, CA 94309 USA
}

\begin{abstract}
An ultra-high vacuum loadlock system capable of operating at high voltage has been added to the SLC Polarized Electron Gun. The unit incorporates facilities for heat cleaning, activating and measuring the quantum efficiency of photocathodes. A tray of up to four photocathodes can be exchanged without bringing the activation unit or gun up to atmosphere. Low voltage quantum efficiencies of $20 \%$ have been obtained for bulk GaAs at $633 \mathrm{~nm}$ and $6 \%$ for a 0.3 micron $\mathrm{GaA}$. layer at $755 \mathrm{~nm}$. Results for other cathodes as well as operational characteristics are discussed.
\end{abstract}

\section{INTRODUCTION}

Polarized laser photoemission from GaAs, cr related III-V compound, photocathodes form the basis for most polarized electron sources currenly in use. Extremcly clean vacuum conditions are required to extend the usable lifetime of these cathodes between re-activations. In addition, sources such as the SLC Polarized Electron Gun (PEG) [1] must function under high voltage conditions (peak ficlds of $\sim 10 \mathrm{kV} / \mathrm{mm}$ ). A high voltage discharge occurring in the gun is capable of irreversibly damagirig the cathode, an event which is enhanced by the presence of $\mathrm{Cs}$ used to activate the photocathode to negative-electron affinity. In the past, the PEG has been baked and high voltage-processed to eliminate breakdown sites on the gun electrodes. The cathode was then installed and the gun rebaked. It has been shown [2] that baking reactivates some breakdown sites, requiring re-processing with potential for cathode damage. Also, we have observed that quantum efficiencies (QE) tend to be higher for cathodes that have not been baked in large systems for long time periods. Cathode replacement requires a lengthy and expensive reprocessing of the gun itself.

A cathode-loading system ("LoadLock") has been added to the PEG to address the concerns detailed above, but its use also adds a valuable capability to the polarized source program: As new, higher polarization cathodes become available, they may be easily introduced into the PEG operating on the accelerator. This approach has proven immediately successful with a thin GaAs strained-layer cathode structure [3].

\section{OPERATIONAL REQUIREMENTS}

Two identical LoadLock units were constructed: one for use at the SLC injector and the second at the Giun Test Facility which consists of a PEG, laser and duplicate electron beam line

* Supported by Department of Encrgy contract DE-AC03-76SF00515.
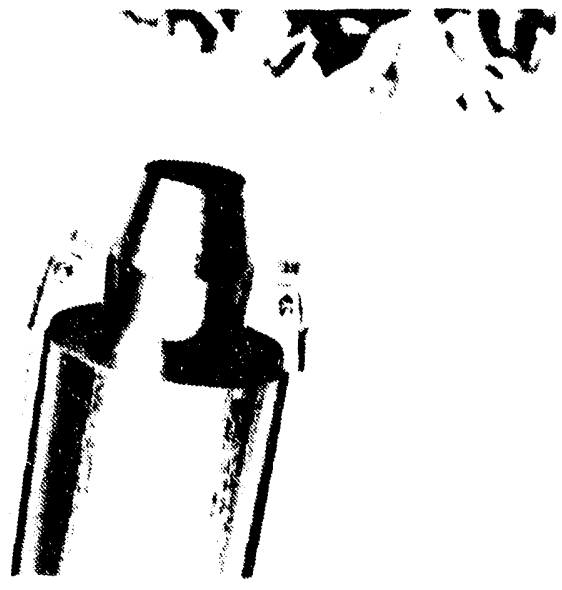

Figure 1. Cathode emitter tube. Mo leaf springs with sapphire roller bearings engage carrier tightly onto the plug end.

up to the first bend magnet. Each LoadLock and PEG incorporates an isolation valve, allowing each to remain independently under vacuum. Connection is via a low-volume short spool piece which can be evacuated and baked-out in a few hours. The functional requirements defined for LoadLock were:

- Heat clean and activate cathodes to negative-electron-affinity using $\mathrm{Cs}_{\mathrm{s}}$ and $\mathrm{NF}_{3}$.

- Measure quantum efficiency.

- Preserve ability to cool the cathode to $0^{\circ} \mathrm{C}$ while in the PEG.

-Vacuum environment consistent with that of the PEG.

- Require no changes to PEG electron optics.

- Bc able to introduce cathodes into LoadLock for use in PEG, preferably without bringing LoadLock itself up to atmospheric pressure.

The cathode cooling requirement has been satisfied by preserving the PEG cathode emitter tube design without modifying the gun structure. The photocathode is mounted on the vacuum side of the tube, and cooling gas is injected from the atmosphere side [4]. Cooling has been useful for extending the period between re-cesiation of cathodes. This requirement, however, means that the LoadLock unit itself is at cathode high voltage during electron beam injection.

\section{LOADLOCK DESIGN}

The structure of LoadLock consists of three sub units: mechanical drive, cathode activation chamber, and cathode tray. Cathode wafers are mounted onto individual Mo carriers using a Ta ring clamp. The carriers can be shuttled between the cmitter tube (Fig. 1) and the cathode tray (Fig. 2) using a system of bellows-sealed linear motions.

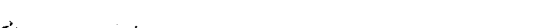

$\therefore, \ldots, y, u=$

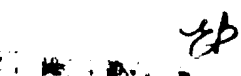

Invited talk presented at the Particle Accelerator Conference, Washington, D.C., May 17-21, 1993. 


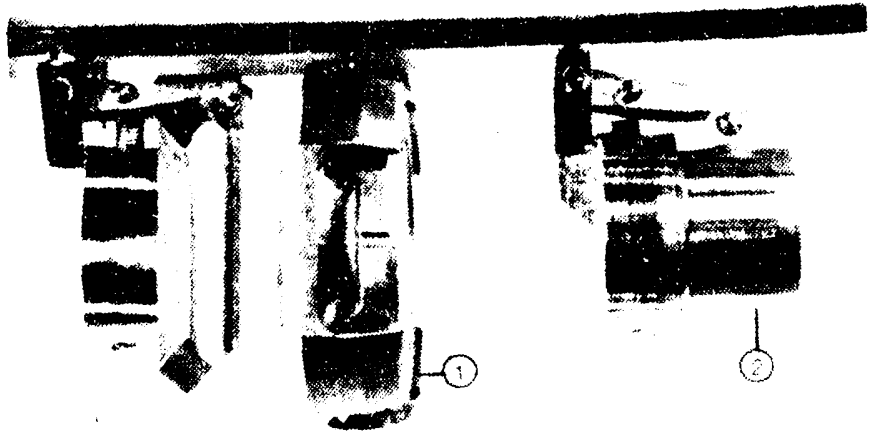

Figure 2. Photocathode carrier tray shows both a position occupied by a Mo wafer carrier (1) and an emply position (2).

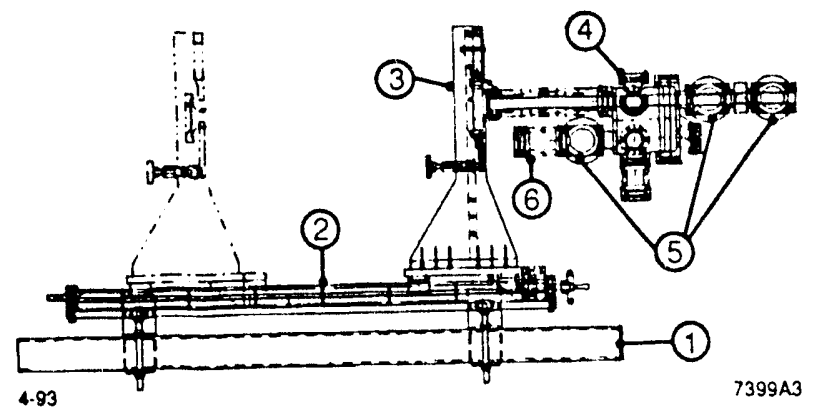

Figure 3. Mechanical drive. 1-Support beam, 2-Rail, 3 Emitter tube transfer assembly, 4-Activation chamber (services not shown), 5-1solation valves, 6-Carrier tray, Item 3 also shown in emilter tube-retracted position for cathode activation/exchange (dashed).

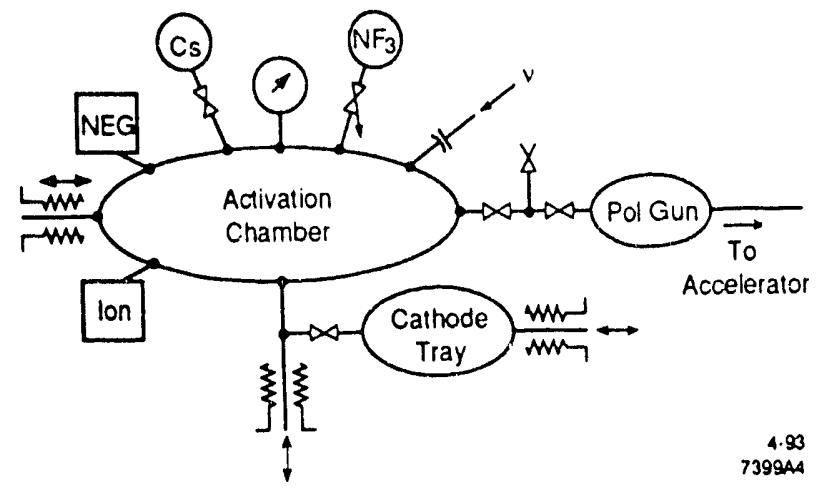

Figure 4. Schematic structure of LoadLock.

The main mechanical drive (Fig. 3) moves the emilter tube through the activation chamber and into the PEG. After insertion, the drive unit is removed and the remaining LoadLock components are enclosed by a corona shield and a high voltage insulating gas containment vessel. After several hours of dry air flow-through, the unit continually stands off a $120 \mathrm{kV}$ potential.

Figure 4 is a schematic of the services available in the cathode activation chamber. The activation chamber is pumped

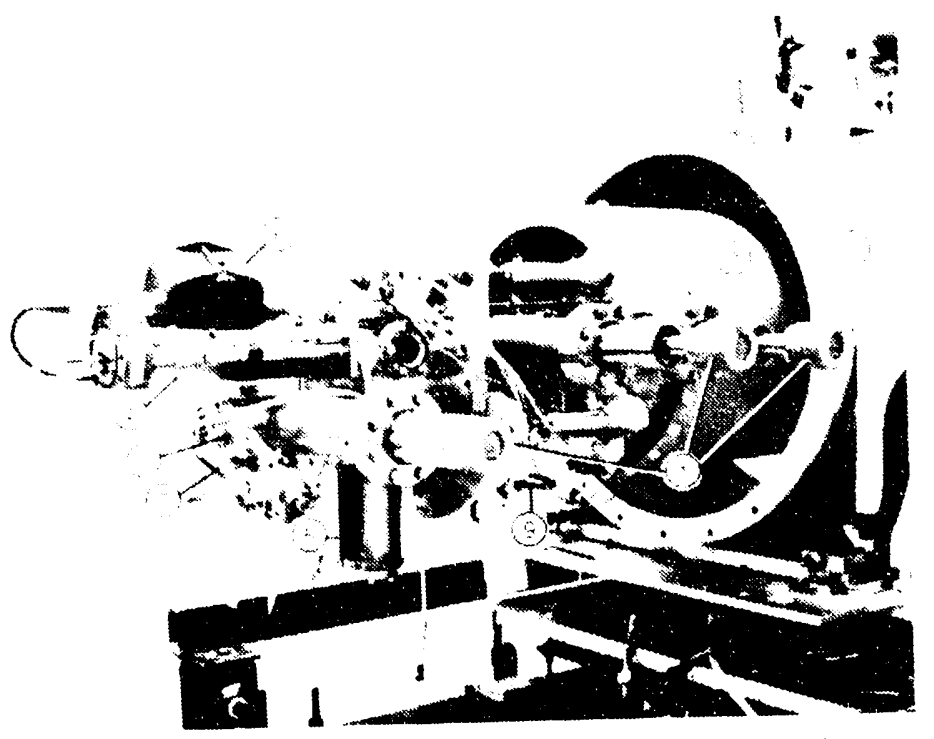

Figure 5. LoadLock attached to the PEG. 1-Isolation valves, 2-Part of $\mathrm{HV}$ gas container, 3-G10 support cylinder, 4-Emitter tube and bellows, 5-Cathode exchange linear motion, 6-Ion pump, 7-NEG pump, 8-Cathode tray, corona shicld and high voltage container not shown.

by a combination of an $8 \mathrm{l} / \mathrm{s}$ diode ion pump (powered by a fiber-optic-isolated supply) and by a room temperature ST707 non-evaporable-getter pump [5]. The residual gas composition is $>99.9 \% \mathrm{H}_{2}$ at a pressure of $<1 \times 10^{-10}$ torr. A gas heater unit inserted into the emiller lube allows heating of SLC $15 \mathrm{~mm}$ diameter cathodes to $-600^{\circ} \mathrm{C}$. During heating, the evolved gas $(>99 \%)$ is $\mathrm{H}_{2}$, which has been shown [6] to be beneficial for removing oxides and hydrocarbons from GaAs surfaces. A completed LoadLock unit connected to a PEG at the Gun Test Facility is shown in Fig. 5.

The cathode tray is separated from the activation chamber by an isolation valve so that a total of four carriers may be used in LoadLock. A laser alignment screen in a carrier is occasionally used for system alignment and then removed from PEG for cathode replacement. The tray stays connected to, and is pumped by, LoadLock during operation.

\section{PERFORMANCE}

LoadLock units were tested in two stages: initially by connection to a simple vacuum chamber containing a cathodeanode electrode structure, photo-electron current collector and light window, and finally, by connection to a PEG at the Gun Test Facility. Bulk $\mathrm{GaAs}(100)$ was used in the first system. $\mathrm{QE}$ 's and life times were measured down to $0^{\circ} \mathrm{C}$. QE's as high as $20 \%$ at $633 \mathrm{~nm}$ and $9 \%$ at $755 \mathrm{~nm}$ were achieved with life Limes at $0^{\circ} \mathrm{C}$, identical to previous PEG performance [4].

Measurements at the Gun Test Facility concentrated on thin GaAs $(300 \mathrm{~nm})$ and $300 \mathrm{~nm} \mathrm{GaAs}$ strained-layers. The latter were used on the accelerator when the first Loadlock/PEG combination was moved into operation. The thin GaAs QE at $120 \mathrm{kV}$ was $6 \%$ at $755 \mathrm{~nm}$, measured at the Gun Test Facility. Full details of SLC cathode performance are reported elsewhere [3], but the current LoadLocked SLC strained-layer 
cathode on the lincar accelerator produces $80 \%$ polarization and $1 \%$ QE at $830 \mathrm{~nm}, 12(1 \mathrm{kV}$.

\section{CONCLUSION}

The addition of LoadLock to the SLC clecuron source has resulted in a marked improvement in source capability and reliability. Lange amounts of C's, associated with high voltage breakdown, have been excluded from the gun. A small channel cesiatior has replaced the effusion cell on the gun proper. This allows remote additions of $C$ s to the cathode during the running cycle when a full re-activation is not required. LoadLock has also allowed a rapid upgrade of source polarization from the $28 \%$ of the 1992 SLC/SLD experimental program toward $80 \%$ in 1993.

\section{REFERENCES}

[1] D.C. Schultz, J. Clendenin, J. Frisch, E. Hoyt, L. Klaisner, M. Woods, D. Wright and M. Zolotorev, "The Polarized Electron Gun for the SLC," 3rd European Particle Accelerator Conference. Bcrlin, 1992.
(2) S. Bajic and R.V. L atham, "A New' Perspective on the Gads Conditioning of High-Voltage Vacuum-Insulated Elecuodes," Journal of Physics D 21, 943 (1988).

(3) J. E. Clendenin, R.K. Alley, H. Aoyagi, J.C. Frisch, C.L. Garden, E.W. Hoyt, R.E. Kirby, L.A. Klaisner, A.V. Kulikov, C.Y. Prescolt, P.J. Sácz, D.C. Schulu, H. Tang, J.L. Turner, M. Woods, A.D. Yeremian and M.S. Zolotorev, "Performance of the SLC Polarized Electron Source with High Polirization," these procecdings.

[4] D. Schulu, R. Alley, J. Clendenin, J. Frisch, C. Garien, E. Hoyt, L. Klaisner, A. Kulikov, C. Prescoll, P. Sácz, H. Tang, J. Turner, M. Wicks, M. Woods, D. Yeremian, and M. Zolotorev, "Polarized Source Performance in 1992 for SLC-SLD," 10th Int. Symp. on High Energy Spin Physics, Nagoya, 1992.

15] SAES Gellers U.S.A., Inc., Colorado Springs, CO 80906.

16] R.W. Bernstein and J.K. Grepstad, "Removal of the Surface Contamination Layer From $\mathrm{CF}_{4}$ Plasma Elched GaAs(100) Substrate by Thermal Annealing in Hydrogen,"J. Appl. Phys. 98, 4811 (1990).

\section{DISCLAIMER}

\begin{abstract}
This report was prepared as an account of work sponsored by an agency of the United States Government. Neither the United States Government nor any agency thereof, nor any of their employees, makes any warranty, express or implied, or assumes any legal liability or responsibility for the accuracy, completeness, or usefulness of any information, apparatus, product, or process disclosed, or represents that its use would not infringe privately owned rights. Reference herein to any specific commercial product, process, or service by trade name, trademark, manufacturer, or otherwise does not necessarily constitute or imply its endorsement, recommendation, or favoring by the United States Government or any agency thereof. The views and opinions of authors expressed herein do not necessarily state or reflect those of the United States Government or any agency thereof.
\end{abstract}



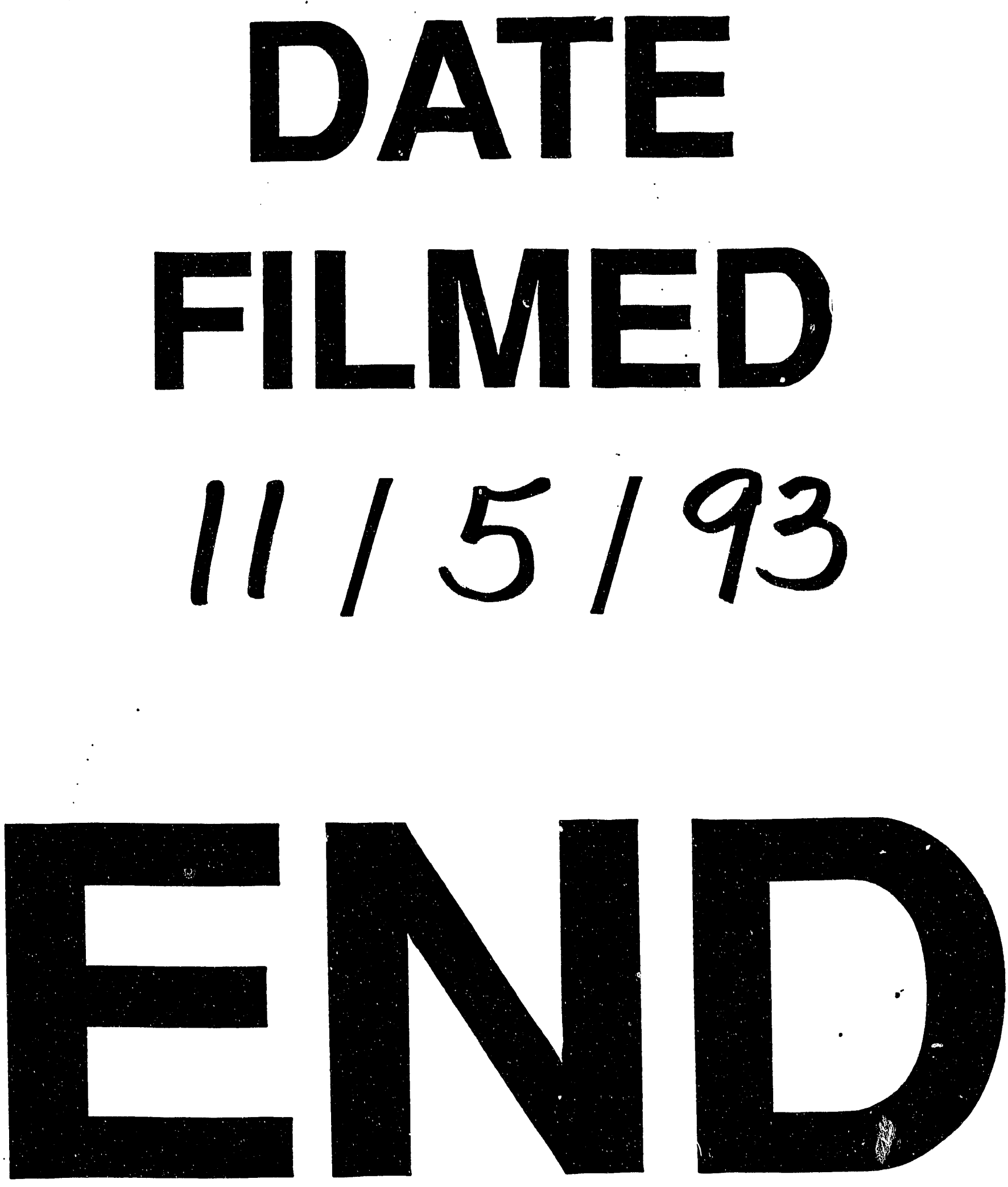
